\title{
Spatial distribution of discards in mixed fisheries: species trade-offs, potential spatial avoidance and national contrasts
}

\author{
Robert Marianne ${ }^{1,{ }^{*}}$, Calderwood Julia ${ }^{2}$, Radford Zachary ${ }^{3}$, Catchpole Tom ${ }^{3}$, Reid David G. ${ }^{2}$, \\ Pawlowski Lionel ${ }^{1}$
}

1 Ifremer, Unité de Sciences et Technologies Halieutiques, Laboratoire de Technologie et Biologie

Halieutique, 8 rue François Toullec, F-56100 Lorient, France

2 Marine Institute, Rinville, County Galway, H91 R673, Ireland

${ }^{3}$ Centre for Environment Fisheries and Aquaculture Science, Lowestoft, NR33 OHT, England

*Corresponding author : Marianne Robert, email address : Marianne.robert@ifremer.fr

\begin{abstract}
:
Since 2015, the European Union gradually implemented the landing obligation (LO). This prohibits at-sea discarding of species under total allowable catch management. Spatiotemporal avoidance strategies and increasing fishing gear selectivity are two complementary levers that could help fishers in reducing the amount of discards. The objective of this paper is to analyse discarding practices of demersal mixed fisheries in the central part of the Celtic Sea to inform on potential spatial avoidance strategies of unwanted catches in a multi-species context. This study provides the first international and fine scale discard maps based on combined observer at-sea data from Ireland, France and the UK, the main countries fishing in the area. Using a suite of multivariate analyses, we identified areas with similar discard profiles, accounting for the multi-species nature of the fisheries. The maps were also derived separately for the three countries to examine national versus general patterns. Strong spatial segregation in effort between the countries, combined with nationally distinct quotas constraints, fisheries targets and market preferences, resulted in limited differences in the species composition of discards, but considerable differences in spatial discard patterns between countries. In theory, the maps based on discards below and above the minimum conservation reference size could inform fishers on areas to avoid but in practice, the spatial ubiquity of some species involved and strong technical interactions between fishing gears limit the possibility of avoiding discards. Some species trade-offs could be identified that might help to minimize adverse impacts of the implementation of the LO.
\end{abstract}

Keywords : Fisheries management, Landing obligation, Discards, Mixed fisheries, Celtic Sea 
51

The European Union Common Fisheries Policy (CFP) was reformed in 2013 (EU 2013), and the regulation stipulates that all fisheries will be subject to the landing obligation (LO) from 2019. It stipulates that all catch from the stocks under Total Allowable Catch (TAC) regulations (or with a Minimum Conservation Reference Size (MCRS) in the Mediterranean) must be landed, prohibiting the common practice of throwing unwanted catches back into the sea. Most European fleets will need to reduce their discards to comply with this new management rule to avoid reducing their fishing opportunities and maximize the revenue from their quota. Discarding rates are still high for some trawl fisheries (Kelleher 2005; Zeller et al. 2018; Pérez et al. 2019), which makes the implementation of the landing obligation quite challenging (Catchpole et al. 2017), knowing that high-grading is prohibited as well. The causes of discarding are diverse and the consequence of several factors including stock dynamics (e.g. seasonality, spatial aggregation), national quota allocation (e.g. low quota share of the TAC), quota availability at fleet or vessel level and potential for avoidance of unwanted catches (e.g. gear selectivity, fishing strategy), mismatch between actual stock level and management measures (TAC constraints on main or non target species) and market drivers (demand and price for fish) (Catchpole et al. 2005; Feekings et al. 2012; Eliasen et al. 2014; Morandeau et al. 2014; Sigurdardottir et al. 2015; Pennino et al. 2017). What is clear is that discarding of fish above and below a Minimum Conservation Reference Sizes (MCRS) have different drivers which need to be considered when designing management approaches (Catchpole et al. 2014).

Making changes to the selectivity of fishing gear is an approach often investigated to reduce discards but avoiding unwanted catches through changes in spatio- temporal fishing strategies is another important strategy which has, however, received less attention. Sea trials of selective gear have been performed throughout Europe with additional meta-analysis (Fryer et al. 2016, 2017) and resources, which collate and summarise how different modifications may influence the escape of different species. These resources aim to make fishermen, net makers and fisheries managers aware of the possible modifications that can be made to fishing gears, and so develop gears with a selective performance suitable for their particular fishery (GearingUp, 2017; O'Neill and Mutch, 2017; SeaFish, 2018). However, the adoption of changes in fishing gear remains a slow process even on a voluntary basis (Eayrs and Pol 2018).

Fishers also have experience-based knowledge on fishing locations of high abundance of juveniles or nontarget species at specific periods of the year. However, this type of information is likely to be at a fine spatial 
scale and specific to fishers personal experience, and not necessarily shared depending on the balance between competition within fisheries and personal gain from being in a collaborative context (Evans and Weninger 2014). Scientists have compiled spatio-temporal catch information that covers most of the fisheries worldwide. A wide range of method have been applied to fisheries data to provide decision support tools and maps to support fisheries management. Multivariate approaches have been used to summarize and describe catches by grouping métiers that have similar landings (Moore et al. 2019) and discards profiles (Erzini et al. 2002), describe the spatial distribution of catches and effort at high resolution (Gerritsen and Lordan 2011) or explore the link between species composition and covariables (Pennino et al. 2017). Other alternate methodologies such as random forest (Vilela and Maria Bellido 2015), redundant maps (Calderwood et al. In press) or nested grids (Pointin et al. 2018) have been developed to provide fishing suitability and hotspots maps. On a complementary approach modeling methods have been used to explain the quantities of each species discarded per trip (Rochet et al. 2002), disentangle effects of environmental and economic variables on catches (Viana et al. 2013; Grazia Pennino et al. 2014; Maina et al. 2018) and provide useful predictions. More recently, bayesian hierarchical models better account for spatio temporal pattern and improve map accuracy (Sims et al. 2008; Paradinas et al. 2016). However, such analyses are rarely designed for, and communicated to, fishers to help them avoid discarding or to inform managers on possible approaches to minimizing unwanted catches.

The Celtic Sea extends from the shelf area west of Scotland down to the western Channel south of England. The area accommodates a high diversity of marine species that support fisheries targeting different species assemblages from pelagic to demersal (Gerritsen and Lordan 2011; Martinez et al. 2013; Mateo et al. 2017; Dolder et al. 2018). The mixed nature of these fisheries leads to high discard rates, especially in the mixed demersal trawl fishery where many species occupy similar habitats and display similar behaviours making it difficult to selectively fish for individual species. The objective of this study is to analyse discarding practices of demersal mixed fisheries in the central part of the Celtic Sea which might provide insight on potential spatial avoidance strategies of unwanted catches in a multi-species context. International analyses are rarely performed because spatial data are not easily accessible to scientists and shared among EU member states and additionally because national fisheries datasets were not initially designed to facilitate pooling to support large spatial scale analyses. 
This study provides, for the first time, international and multi species discard maps based on shared data from the observers at sea programmes from Ireland, France and the UK, the main fishing countries in the area. Our approach focusses on species assemblages instead of individual species maps to explicitly account for the multi-species nature of the discards. This might help stakeholders to pinpoint trade-offs between target and non-target species discards for seven of the main demersal species of roundfish and flatfish of the Celtic sea. We set out to assess the two size categories of discards separately providing multi-species spatial maps of above and below MCRS discards, and assess whether both categories occurred in the same location. A further aim was to produce maps showing country specific data to enable comparisons to be made on discarding patterns.

\section{Material and methods}

\subsection{Data source}

The onboard observer programme is part of the European funded Data Collection Framework (DCF, Council regulation No 199/2008) used as a basis for the assessment and management of EU fisheries. Onboard observer programmes provide data on catch composition, as well as the characteristics and condition of the fishing operation. They constitute the only systematic and quantitative source of information on discarding practices at sea. Based on national sampling schemes, observers embark on commercial fishing vessels and report the geographical positions, gear, mesh size, fishing time and target species of all hauls (Rochet et al. 2002; Borges et al. 2005; Enever et al. 2007). All species of fish and commercial invertebrates from the landed and discarded components are also counted, weighed and measured (with subsampling performed when necessary) for a subset of hauls.

We extracted data for 2010-2014 from the French, English and Irish observer at-sea databases for the central Celtic Sea ecoregion $\left(49-52^{\circ} \mathrm{N} ; 5-11^{\circ} \mathrm{W}\right)$. We focused our analysis on the main TAC managed species targeted in the area and for which MCRS are defined in European legislation for the Celtic Sea : Gadus morhua (MCRS at $35 \mathrm{~cm}$ ), Lepidorhombus whiffiagonis (MCRS at $20 \mathrm{~cm}$ ), Melanogrammus aeglefinus (MCRS at $30 \mathrm{~cm}$ ), Merlangius merlangus (MCRS at $27 \mathrm{~cm}$ ), Merluccius merluccius (MCRS at $27 \mathrm{~cm}$ ), Pleuronectes platessa (MCRS at $27 \mathrm{~cm}$ ), Solea solea (MCRS at $24 \mathrm{~cm}$ ). MCRS did not change in this areas over the study period. National observer data were separated based on species and MCRS (fish above and below MCRS) 
and raised to haul level using length-weight keys providing total weights for above and below MCRS discards of each species. Nephrops is a commercially important and targeted species in the Celtic sea. However, the data suggests there is no above MCRS discards of Nephrops for most of the countries, leading to distinct list of species between above and below MCRS and between countries preventing us from including Nephrops norvegicus in the study.

\subsection{Discard maps}

The objective of the analysis was to identify and describe areas with similar discard profiles, using a combined set of multivariate methods (principal component analysis (PCA) and hierarchical classification) as described in (Mateo et al. 2017).

Each fishing operation (haul) was attributed to a grid cell of $10^{\prime *} 10^{\prime}$ (which corresponds approximately to a grid of $0.16^{\circ}$ longitude $* 0.16^{\circ}$ latitude), based on mean haul position. Eight data sets were created: above and below MCRS discards for each country separately (France, Ireland and the UK) and all countries combined in a unique data set. The national databases were first joined to provide an average overview of spatial discards patterns based on the biggest possible amount of data. The combined data set included 8147 hauls over 326 cells with the number of fishing operation per grid cell ranging between 1 and 97, with an average of 16 and median of 12 . Secondly, national databases were analysed separately to address national contrasts. Maps illustrating the number of hauls per grid cells are presented in the Supplementary data (Annex 1). Because the discarding process is highly variable, we removed cells having less than three observed hauls, which reduced the number of cell retained for further analysis by $15 \%$ for the combined data set and up to $30 \%$ for the Irish datasets. It was difficult to further disaggregate the data by year, season, gear and country/year, country/season, gear/season, gear/country etc... while maintaining good representativeness and spatial coverage to enable comparison. We aim to provide an overview at the scale of the Celtic sea while avoiding presenting a simple discard atlas. Nonetheless, analyses were performed for each quarter and each year in the supplementary material (Annex 4) and used to elaborate the discussion. For each data set, we calculated the proportion of discards of each species in relation to the total discards per cell (over the period 2010-2014). This approach allows us to consider the impact of fishing in an area over a species assemblage rather than focusing on the separate impact on each species. An alternative approach would have been to use discards quantities, which would have allowed identifying areas with low discard amounts versus high discard amounts. However, proportions are less sensitive to changes in 
quantities and stabilises the species composition over time despite changes in effort, particularly for species that are relatively abundant (Gerritsen et al. 2012). The aim of the LO was not to reduce the proportion of discards, but the absolute amount of discards. As such, both absolute and relative approaches are of interest and bring complementary information.

As suggested by Deporte et al. (2012), a centered and normalised PCA was applied to this matrix prior to hierarchical cluster analysis (HCA using Ward's minimum variance method). This approach helps in reducing the dimensionality of the data and identifies the main recurring species combinations that explain the greatest variation (Legendre and Legendre 2012). Only the first six axes of the PCA (accounting for more than $80 \%$ of the explained inertia) were kept for subsequent application of HCA to reduce random fluctuations. This was done to improve the partitioning and homogeneity between and among classes (Legendre and Legendre 2012). Statistical analyses were performed independently for the eight case studies. The most appropriate number of clusters was set at 5 for each data set, representing around 50 $60 \%$ of the variance and a trade-off between spatial homogeneity and complexity . The percentage of variance explained as a function of the number of clusters was provided in the supplementary material (Annex 3), along with maps derived with 10 clusters. The spatial clusters were described according to the relative abundance for each species in clusters and spatially represented on a map using a unique colour. Multi-species discards cluster maps were derived for the eight data sets independently. However, to facilitate comparison between maps, similar clusters in terms of species composition across case studies were given the same colour code. In some case, matching was difficult illustrating structural differences in the data between the eight case studies. The spatial distance between the grid cells was not taken into account, so any spatial patterns that emerge from the analysis are the result of similarities in the discard composition of neighbouring cells (as in Gerritsen et al., 2012; Mateo et al., 2017).

\subsection{Spatial relation between above and below MCRS discard clusters}

Observer-at-sea data allows us to investigate the fine scale spatial link between discards that are below and above MCRS as information were collected at the haul level. The spatial relationship between $>$ and $<$ MCRS discards of species is investigated by comparing how the classification of cells within each cluster of undersized data matches with the corresponding cell in the above MCRS data set .This highlights whether 
similar clusters of species are identified for both below and above MCRS discards or if species are spread out between different clusters in the two data sets. .

Analyses were performed using the ade4, labSv and mapplots packages available for R.3.3.3 (http://www.Rproject.org/).

\section{Results}

\subsection{Irish discard maps}

Based on observer data, the most important species discarded in terms of tonnage for Ireland in the area studied was haddock, followed by whiting, hake, cod, megrim and plaice. The percentage of undersized discards in the total is $51 \%$ for haddock, $43 \%$ for plaice, $31 \%$ for cod, $20 \%$ for whiting and $17 \%$ for hake (Supplementary- Annex 2).

The first point to note from the cluster analysis on $<$ MCRS data, is that two of the seven species (cod, and plaice) were found predominantly ( $>50 \%$, Table 1a) in one cluster each, suggesting that the $<$ MCRS discards of these species tend to originate from separate catches. This statement strengthened with 10 clusters for four of the seven species (Supplementary, Annex 3). The map in figure 1a shows that the cells occupied by these clusters are often widely distributed in space. This is particularly the case for cluster 1 which is dominated by cod ( $62 \%$ of the $<$ MCRS discards of cod were in cluster $1 /$ red cells in Figure 1 a, Table 1 ). Cells of cluster 1 are spread out across the southern part of the study area in individual clumps. On the other hand, $78 \%$ of $<$ MCRS plaice discards were in cluster 5 (in pink), and there is a clear patch of these cells in the coastal zone south of the Irish coast at around $51.8^{\circ} \mathrm{N}-7.2^{\circ} \mathrm{W}$. The only species where the bulk of the $<$ MCRS discards were not found in one cluster was haddock, which was found spread over three clusters ( and up to seven clusters in the case of 10 clusters analysis), with the highest quantities found in cluster 3 in light blue (44\%, patches from the south coast of Ireland to the central Celtic sea) and cluster 1 and 4 in red and purple ( 24 and $22 \%$ respectively \%), and in smaller quantities in clusters 2 and 5. Some clusters were characterized by a more multispecific assemblage. Cluster 4, in purple, for example highlights the cooccurrence of undersized discards of whiting, haddock, sole and cod in an area centered at $51^{\circ} \mathrm{N}-6.5^{\circ} \mathrm{W}$. When increasing the number of clusters these areas are closely associated with cluster 7 , which is 
characterized by a larger proportion of whiting discards compared to the other species. Undersized haddock is caught together with cod in the light green cells (cluster 4), which are scattered over the entire study area. Cluster 2 (in orange) has contributions from megrim and hake, and in concentrated mainly in the south-west of the study area. When increasing the number of cluster $<$ MCRS megrim and hake are split in distinct clusters (2 and 5).

Unlike the case for the $<$ MCRS discards, the pattern is less clear for the $>$ MCRS fish (Figure 1b). Cluster 1 consists of more than $50 \%$ cod (Table 1) but is associated with many other species ( mainly hake and haddock) with little evidence of a distinct spatial pattern, while cluster 5 (in pink) had more than $75 \%$ of $>$ MCRS plaice and $82 \%$ of $>$ MCRS Sole and is distributed across inshore waters along the south Irish coast. Some of the other clusters were dominated by a single species. For instance, cluster 2 (in orange) was dominated by megrim, and spatially clustered in the southern part of the area (between $50.5-49^{\circ} \mathrm{N}$ and 7$9^{\circ} \mathrm{W}$ ). . Cluster 4 (in purple), characterized by both whiting and haddock, was concentrated in the north of ICES area VIIG, and up the coast in an area bound by $51-52^{\circ} \mathrm{N}$ and $6-7^{\circ} \mathrm{W}$. When increasing the number of clusters to 10, Cluster 7 (in dark blue), dominated by whiting was found mainly in the same areas. As with the $<$ MCRS case, the $>$ MCRS haddock and whiting were identified across a number of clusters. Clusters 1 and 3 (in red and light blue), characterized by a more multispecies assemblage, occupied an wide area.

Despite little obvious match at first sight, some similarities exist between the maps for above and below MCRS fish. Features in the <MCRS discard map (Figure 1a), such as clusters 4 and 5 in the northeastern part of the Celtic sea, can also be found on the >MCRS map (Figure 1b). This would tend to suggest that both categories of whiting, haddock and cod were targeted and subsequently discarded in the same area. When increasing the number of clusters spatial overlaps between both categories of plaice and cod tend to disappear but remain for whiting and haddock. The relationship between the clusters for the two size categories can be explored further in the bar charts in Figure 2. If $<$ and $>$ MCRS clusters were found in similar area for each case study the first bar would be red, the second bar would be orange, the third light blue, the fourth purple and the fifth pink. More than $50 \%$ of the cells identified as being in $<$ MCRS cluster 3 and 4 and 5, were also in the same cluster for >MCRS discards, (Figure 1, Table 1, Figure 2). Species composition matches between $>$ and < MCRS clusters can be therefore be found. However, for clusters 1 and 2 the spatial overlap was relatively small .

\subsection{French discard maps}


Based on observer data, the most important species discarded in terms of tonnage for France in the area studied was haddock, followed by whiting, cod, hake, megrim and plaice. The percentage of undersized discards in the total is $62 \%$ for sole, $37 \%$ for haddock, $32 \%$ for cod, $18 \%$ for plaice, $14 \%$ for whiting and 13\% hake (Table S1).

As was the case for Ireland, whiting, plaice and cod $<$ MCRS discards were found predominantly $(>50 \%$, Table 1b) in one cluster each, suggesting that the <MCRS discards of these species tend to be caught separately. This statement extends for most of the species excluding haddock in the 10 clusters analysis. However, the map in figure 1c shows that the cells occupied by these clusters are often widely distributed in space. Haddock was found spread over four clusters, with the decreasing quantities found in clusters 31-4-2 (41-23-19-15\% respectively). There are clear patches of cluster 3 cells around areas $49-50^{\circ} \mathrm{N} 5-7^{\circ} \mathrm{W}$ and $50.5-51.5^{\circ} \mathrm{N} 5-7^{\circ} \mathrm{W}$. Several clusters were characterized by a more multispecies assemblage. Cluster 1 (in red, Figure 1c) for example highlight the co-occurrence of undersized discards of cod and haddock over the entire area west of $7^{\circ} \mathrm{W}$. The co-occurrence of undersized discards of whiting and haddock (cluster 4 in purple) are identified together in the north east of the area $\left(51-52^{\circ} \mathrm{N} 5.5-6.5^{\circ} \mathrm{W}\right)$ while the co-occurrence of undersized discards of hake and megrim and sole (cluster 1 in red) cover an important area in the central area of the Celtic sea $\left(49.5-51^{\circ} \mathrm{N} 7-9^{\circ} \mathrm{W}\right)$.

Distribution in space of statistical clusters are less clear for >MCRS discards (Figure 1d), as observed with the Irish data set. The co-occurrence of $>$ MCRS discards for most of the species within cluster 5 (pink) are scattered across the entire area east of $8^{\circ} \mathrm{W}$. Two clusters show more patchy features; Cluster 4 in purple, characterized by whiting and plaice, is concentered in the north east while cluster 2 in orange, characterized by hake and megrim, is spatially concentrated in the central part of the study area. When increasing the number of clusters, most of the clusters show little obvious spatial pattern and cells close in space are often classified in different clusters. One can notice that oversized discards of sole and plaice are disentangled from the co-occurrence of whiting and haddock, with the formers being mainly encountered in coastal areas (cluster 8 and 10 versus 9). .

Comparisons between Figure $1 \mathrm{c}$ and $1 \mathrm{~d}$ inform on the ability to avoid $<$ MCRS and $>$ MCRS catches in the context of the LO. The more that discards of a single species and size category dominate a cluster in a specific area, the higher the potential for spatial avoidance. In contrast where a single species dominates an area for both size categories there is higher potential for introducing selective measures to avoid <MCRS catches. 
We identify few spatial similarities between the two maps with both 5 and 10 clusters. However, both categories of whiting and haddock seem to be caught in the same area located in Nephrops grounds in the north east of the Celtic Sea. This indicates that <MCRS fish are difficult to avoid in this particular area when targeting adult fish. As with the Irish data, results based on French data and 10 clusters support the idea that plaice are fished and discarded in the same coastal area (Annex 3, cluster 8,10). In contrast, well defined clusters such as cluster 3 (in light blue Figure 1c) of < MCRS haddock discards, especially the southern east patch, is spread out in various clusters of > MCRS discards including >MCRS whiting (cluster 4) and cod (cluster 1) (Figure 2-FR). The spatial mismatch between cluster 1 for $<$ and $>$ MCRS discards supports the idea that both categories of cod were to some extent caught in different places (Figure 1c, Figure 2-FR). Spatial overlaps was quite good for clusters 2 and 5 (Figure 2-FR), however they both have much higher area coverage in the $>$ MCRS maps compared to $<$ MCRS maps.

\subsection{UK discard maps}

Based on observer data, the most important species discarded in terms of tonnage for the UK in the area studied were cod and haddock, followed by megrim, plaice, hake and whiting. The percentages of $>$ and $<$ MCRS discards vary between species. The percentage of undersized discards in the total is $42 \%$ for haddock, $40 \%$ for plaice, $26 \%$ for sole and $12 \%$ for whiting (Table S1). For the remaining species (cod, hake and megrim) less than $6 \%$ of those discarded were below MCRS.

Two up to five of the seven species, depending on the number of clusters in the analysis, were found predominantly in separate clusters, suggesting that the $<$ MCRS discards of these species tend to be caught separately (Table 1c). In contrast to French and Irish maps, clusters are often found closer together supporting stronger spatial homogeneity (Figure 1e). Clusters 3 (in light blue) is essentially located south of $50^{\circ} \mathrm{N}$ and east of $7^{\circ} \mathrm{W}$ with $47 \%$ of the $<$ MCRS discards of haddock.. Clusters 5 (in pink) is concentrated along $5^{\circ} \mathrm{W}$ at the mouth of the Bristol Channel and is characterized by $70 \%$ and $90 \%$ of undersized plaice and sole discards respectively. The 10-cluster analysis tends to separate sole and plaice discards in space. The co-occurrence of <MCRS discards of haddock and whiting are found in cluster 4 north of the Scilly Isles. In contrast with the 10 cluster maps, the 5 cluster maps for the >MCRS fish (Figure 1f) highlight well-defined patches; however most of the clusters are made of multi species assemblages. Only three clusters were 
characterized by a single dominant species (> 50\%, Table 1c). Above MCRS discards of megrim and hake are well distinguished (with cluster 4 more north than cluster 2), while being merged in the $<$ MCRS analysis. Oversized discards of cod are widely distributed over the central part of the Celtic sea and south of the Scilly Isles (cluster 1). Clusters 3, 4 and 5 were characterized by multispecies assemblages with the former being localized south of $50^{\circ} \mathrm{N}$ (haddock whiting, megrim) , and the latter two north of $50^{\circ} \mathrm{N}$ (cod, hake, sole, plaice and whiting).

Spatial coverage of the two maps (Figure 1e and 1f, Figure 2-UK) indicates that clusters of $<$ MCRS fish catches are found closer to the shore than clusters of $>$ MCRS fish. The relationship between the clusters for the two size categories is further quantified in Figure 2, where we can see for example that most of the orange cells of cluster 2 for $<$ MCRS data (dominated by megrim and haddock discards) are included in cluster 2 for $>$ MCRS data. The results also indicate that both plaice and sole are caught in the same general areas (pink cells) and both $<$ MCRS and $>$ MCRS are caught in these areas (Figure 2, cluster 5). When considering the $<$ and $>$ MCRS discards, separately, different species dominate discards in different areas, in particular sole, hake and megrim but also haddock, whiting and cod to a lesser extent, indicating that some spatial avoidance of these species and size classes could be achieved.

\subsection{International discard maps}

For the $<$ MCRS discards, the analysis of the combined data set reveals clusters defined similarly as those identified from the data analysis carried out separately for each country (Table 1d). Two clusters are dominated by a single species in all three country datasets and the international dataset : clusters 1 (cod) and 3 (haddock). There were several clusters with more than $10 \%$ of the haddock discards, and one of these (clusters 1) was apparent in all individual country data and for the ensemble. While the multi-national clusters were broadly defined by similar discard profiles to the national, the spatial distribution of clusters were less consistent between the different analyses. Some clusters were located in similar areas for the separate and combined international maps, such as $<$ MCRS cluster 5 in pink and to a certain extent cluster 3 and 2, which remain spread out across the area or on the southern area along the slope of the continental shelf. Because of the spatial segregation of discards and effort between countries, some clusters of the combined analysis appear as the sum of the three countries maps. This is particularly the case of cluster 3 (in light blue, Figure 3) which results in the addition of the patch from the south coast of Ireland to the central Celtic sea identified on the Irish maps (Figure 1a), the patch around areas $49-50^{\circ} \mathrm{N} 5-7^{\circ} \mathrm{W}$ and $50.5-$ 

the UK maps (Figure 1e). The co-occurrence of undersized discards of haddock and whiting identified in the northern part of the area between Irish and UK coasts on French and Irish maps is well defined on the international maps. Given the surface area cover by cluster 3 in light blue, 5 clusters seems insufficient to describe > MCRS spatial pattern at an international level. Maps with 10 clusters shown in the supplementary provide a more detailed and likely more appropriate description of the spatial discard pattern.

For >MCRS fish, greater differences appear between the composition of clusters (table $1 \mathrm{abcd}$ ). The relative abundance for each species in clusters are especially different between national and international analyses for clusters 1,2 and 5 . It is not easy to compare the individual maps in figures $1 \mathrm{~b}, \mathrm{~d}$ and $\mathrm{f}$, however, one can see that cluster 2 (in orange Figure 3) combines the >MCRS megrim patches identified on the Irish and UK maps in the south east of the area. As with individual national analysis, spatial overlap between $<$ and $>$ MCRS clusters is medium to low ( $<50 \%$ ), except for clusters 4 and 5 (supplementary, Annex 2).

Presenting all national clusters together is feasible with 5 clusters but becomes difficult with an increasing number of clusters; however, each cluster can be mapped separately for all countries. Figures 4 and 5 illustrate what can be done to facilitate comparisons between the different national datasets. Figure 4 helps in comparing cluster locations between countries in overlapping cells of the same cluster (Figure 4 ab for cluster 8 and Figure $4 \mathrm{~cd}$ for cluster 1 ) identified by France, Ireland and the UK for $>$ and $<$ MCRS discards separately based on the results of the 10 clusters analysis. The two examples (for clusters $1 \& 8$ ) show clear differences in spatial patterns. For cluster 8, the discards of fish above and below MCRS have very similar distributions, so it would be difficult to fish adult plaice in areas with few $<$ MCRS plaice. Conversely, we can see quite different spatial distributions for cluster 1, which is dominated by high cod discards. From this it is clear that adult and juvenile cod are discarded in distinct areas, with adults being discarded further north and west than the juveniles. Figure 5 helps in identifying the spatial match and mismatch between $>$ and $<$ MCRS discard clusters, using the example of cluster 9 and the four data sets. Using the whole combined dataset, we can see that cluster 9, characterized by discarding of haddock and whiting, is most prevalent in an arc along the Irish coast and down to Cornwall. This pattern is less visible in the national data. The UK and Irish data taken together include much of the area seen in the combined data set. The distribution of clusters are in very similar areas, with little potential for avoidance. 
It is well known that >MCRS discard quantities evolve within a year due to intra annual growth (which can be important for gadoids) and movement from coastal nursery to more off shore feeding ground which often correspond to fishing grounds. We illustrate what can be done to facilitate comparison between quarters based on the 5-cluster analysis on the combined data set. Spatial coverage and species composition of cluster 5 is stable through time (Supplementary, Annex 4), even if the proportion of gadoids increases slightly at the end of the year. Cluster 4 is characterized by the co-occurrence of haddock and whiting in addition to sole in quarter 2 and cod in quartier 4. Its spatial distribution evolved with a clear distinct patch north of the Celtic sea in quarter 3 and a more widespread distribution in quarter 4. Cluster 3 accounts for the higher percentage of haddock discards and all year long it is always distributed over the entire area even if a clear patch appears south of the Scilly Isles at quarter 4. Species composition and spatial distribution are less consistent between quarter for clusters 1 and 2, even if cluster 2 is recurrent along the continental slope. However, it is difficult to assess whether the changes in spatial distribution are due to lack of observation in some areas in some quarters and if species composition results in change in biotic environment or if is an artifact of the underlying sampling scheme, métier, gear, etc ...

Multinational spatial descriptions of landings (Mateo et al. 2017) and métier (Moore et al. 2019) were already performed in the Celtic Sea. However, to our knowledge, this study is the first multispecies, fine scale, spatial analysis of discards conducted at multinational level in the area. The core aim was to use observer data to identify where commercial fish were discarded and with what other species. It provides an overview of discard locations at species levels for both below and above MCRS discards in the central region of the Celtic Sea. It also sought to identify the spatial correspondence, or lack of, for discards above and below MCRS between countries and all countries combined.

Considering first the analysis of the fish below MCRS. Knowing where these undersized fish are is the key to avoiding their capture. Indeed, the present study has shown that there are clusters of undersized discard events dominated by a single species, and that, at least in some cases these can be delineated geographically. Species distribution of < MCRS fish are consistent with literature on spatial distribution of species and nursery grounds in the Celtic sea for hake (Kacher and Amara 2005), whiting (Verdoit 2003; Persohn et al. 

2009) and flatfish (Maxwell et al. 2009). However, our analysis have the advantage of bringing all this information together on a single map. When zooming out from species to communities, our results conform to bathymetric and latitudinal clines in fish distributions and abundances with three main assemblages : i) the roundfish species (haddock and whiting) separated from the flatfish (plaice, sole) and the deeper water assemblage (megrim, hake and anglerfish) (Martinez et al. 2013; Dolder et al. 2018). Avoiding undersized catches by avoiding these "hot spots" may appear simple for a single species but will be much more complex in a mixed fishery. However, the mapping may help reduce the likelihood of catching these unwanted fish, while not eliminating it. We have shown, for instance that $<$ MCRS fish were found predominantly in near shore areas along the coast, especially for sole, plaice and whiting and in particular when examining the English dataset. It is clear, therefore, that depth and to a lesser extent substrate are important variables for describing the main driver of similarities and differences in distributions and abundances for the different species (Dolder et al. 2018). However, using these aggregated data, it is not possible to conclude whether this is due to the distribution of the fish or the gear and mesh sizes used in these areas. Discrete patterns, where undersized haddock and whiting co-occurred, were also identified in the north east of the Celtic sea (between $50-51^{\circ} \mathrm{N}$ and $6-7^{\circ} \mathrm{W}$ ). These fishing grounds are also those where Nephrops is heavily targeted (Sharples et al. 2013; Mateo et al. 2017). While this study did not include Nephrops (due to previously described data issues), métiers targeting this high value species are included through their catches of other species. These métiers are likely to substantially drive discards of $<$ MCRS haddock and whiting in such areas, highlighting the need for gear modifications to eliminate such undersize whitefish catches from the

\section{Nephrops fishery}

As with <MCRS fish, identifying where discards of $>$ MCRS were abundant, and then avoiding such areas, has the potential to mitigate the choke problem to some extent. The findings and maps from this study suggest that there may be some potential in this approach. For instance, we identified clear clusters dominated by megrim, hake and whiting for all three countries separately and when all countries were analyzed together. In the 10 cluster analysis the >MCRS megrim cluster showed two areas of concentration, "hot spots", south of $50^{\circ} \mathrm{N}$, identified by the Irish and UK data set. Another, more multi-species cluster including whiting also showed similar hot spots on both French and Irish > MCRS maps. The hake cluster while prominent at the shelf break was also found scattered across the shelf (Kacher and Amara 2005; Mateo et al. 2017). Discards of other species such > MCRS cod, while dominating a single cluster, were spatially scattered across the study area. Above MCRS haddock were found in several clusters, and were also scattered across the study 
area (Verdoit 2003; Dolder et al. 2018). Despite the extent to which the different clusters are aggregated or scattered across the Celtic Sea, it still may be possible for industry to use these data and resultant maps to identify where a given target species might be caught, in the absence of choke species, or to inform that in a given area there is high risk of encountering fish they may wish to avoid (as quota is used up).

Under an effectively implemented LO, fishermen will be motivated to avoid catching <MCRS fish and quota restricted species. In our analysis, we found that for several species there was spatial overlap in the clusters for above and below MCRS dominated by the same species, for example whiting, megrim, hake and plaice. This indicates that fishers could potentially avoid locations where these clusters occur and avoid catches of those species without losing other wanted catches. If, however, they wanted to target these species, they would risk taking high $<$ MCRS catches also, unless the selectivity of the gear was modified. Even where the spatial distributions are not discrete and there are no "hot-spots", it should still be possible to use the results of these analyses to show what a fisher would be likely to encounter if he were to fish in a particular area, assuming this average annual pattern properly reflects what happens at any month in the year. If the area they would like to fish has a high likelihood of including high unwanted catches of, say, cod (Cluster 1), and they are close to quota for cod, they may wish to avoid this area. In some cases, as seen for plaice and sole caught by the UK fleets, discards of $<$ MCRS and $>$ MCRS for the same species strongly overlap which suggests there is opportunity to avoid these catches by fishing elsewhere. Certainly work previously conducted by Calderwood et al (In Press) indicated that the use of such mapping techniques to better target or avoid certain species could extend fishing opportunities under the LO, and the maps presented in this paper could assist further with this. There are few certainties in this approach, however, these data provide additional information that fishermen can use to make informed decisions about where they fish. In addition to the work presented in this study, the magnitude of discards per grid cell would be a valuable additional information source for fishermen regarding the risk of getting substantial unwanted catches. However, the raising procedure of discards requires a dedicated amount of work, especially when dealing with multi species catches in mixed fisheries made of international métiers and fleets.

For the purpose of this study, data from the various national métiers were pooled together in order to provide a general overview of the spatial distribution of discards. However, fishing methods affect catches and in the Celtic Sea strong spatial segregation in fishing efforts per gear (Mateo et al. 2017) and countries 

observed between the three country's maps. Fleet and métier based discard descriptions has support an important amount of literature in the Celtic sea (Rochet et al. 2002; Borges et al. 2005; Enever et al. 2007; Pointin et al. 2018). Due to the spatial segregation between gears, comparison between métier would be difficult when one of our objective was to provide an overview on the entire area. Nonetheless, the analysis could be implemented at métier level to address specific requests from the industry, with some caution being exercised dependent on the quantity of data available. The UK fleet in the study area is mainly composed of beam trawlers targeting benthic flatfish species along the coast, while the otter trawl gears used more predominantly by France and Ireland are known to have higher catch rates of roundish (Fraser et al. 2008). Differences observed between the maps produced per country may also, to a certain extent, be explained by the fact that they did not face the same quota constraints (Table2). Average quota uptake for Ireland was close to $100 \%$ for all the stocks considered except for plaice $7 \mathrm{fg}$ and sole $7 \mathrm{hjk}$. Landings were below the fishing quotas for the UK except for haddock, plaice 7hjk and megrim with some year-to-year fluctuations. Mean percentage of quota uptake for France was also below $100 \%$ for most of the stocks (with some variability depending on the year), except for the two stocks of plaice and sole 7hjk. In light of this, the balance between $>$ and $<$ MCRS discards by species and countries presented in Table S1 suggests that discarding is not only the result of constraints on TAC and quotas but highlights the influence of potential market issues. It is recognized that the discard patterns observed have been influenced by the specific conditions for the vessels during each of the sampled trips with regard to quota availability and response to market opportunities.

471 This study was focused on the potential to avoid catching unwanted fish in the first place, but at best that is 472 likely to reduce, not eliminate, the impact of the LO. The necessary parallel and complementary response 473 will be to modify the selectivity of the fishing nets. However, it is impossible to design gears with so called 474 "knife-edge" selectivity, where all fish of one species are retained over MCRS, and the rest escape. Under the 475 LO, all catches of $>$ MCRS must be landed which leads to the risk of choke events for restricted quotas 476 (Schrope 2010), whereby once the quota is reached for one species in a mixed fishery, fishing has to stop to avoid any further over-quota catches. In mixed fisheries, different species have different MCRS, catchability and behaviors in the net. Selectivity measures may represent part of the solution (Fauconnet and Rochet 2016), but precisely matching the quota available to a vessel operator with the catch composition using only 
gear selectivity changes is unlikely. Therefore, there will always be a trade-off, the more undersized fish we allow to escape, the more over MCRS fish also escape.

In the period of this study, haddock TACs have been exhausted every year for all three nations (Table 2), leading to high discard rates. Undersized discards of haddock account for 40 to $50 \%$ of national discards (Table S1). Under the LO, previously discarded fish will now count against quotas, therefore there is a direct incentive to avoid undersized fish in order to maximize the revenue from quotas and minimize choke risk. Here we show that for species such as haddock, for which $<$ MCRS haddock discards were found in many of the $>$ MCRS clusters, for all three nations, across the entire area, the modification of gear selectivity will be an absolute necessity in addition to avoidance behaviour. Historically, discards of fish above MCRS has often been related to quota constraints e.g. (Batsleer et al. 2015). However, whiting in the Celtic sea showed a different picture. International TAC uptake over the study period is around $60 \%$, with low quota uptake for France and UK, but almost $100 \%$ for Ireland. Nonetheless >MCRS discards account for $80 \%$ of the discards suggesting strong market issues influencing discards. Our analyses highlighted that whiting and haddock were often caught and discarded together, as also highlight in (Mateo et al. 2017; Moore et al. 2019). The maps derived with 10 clusters indicate that avoiding $<$ MCRS discards of haddock while not reducing caches of above MCRS whiting would be possible by fishing an area identified in the French and UK data south of the Scilly Isles. In the case of megrim in the Celtic sea discard rates were around $20 \%$ while quotas were not entirely taken except for the UK and $90 \%$ of discards for the three countries consisted of individuals >MCRS, which suggests market drivers instead. As with the North Sea megrim stock, discarding in the Celtic Sea could be also related to the higher susceptibility of megrim to bruising i.e., some body damage from abrasion with species like gurnards or boarfishes in the codend (Macdonald et al. 2014). As bruised catches are less appealing to buyers or fetch lower prices, discards of marketable fishes (in terms of MCRS) seem more likely to occur. For plaice, both international TAC and national quotas were constraining leading to high discards rates of >MCRS fish for Ireland and UK. Under the LO, such a non-target species can potentially choke both flatfish and whitefish demersal fisheries (Catchpole et al. 2017; ICES 2018). Comparison of discards maps of the three countries indicates that both above and below MCRS plaice discards were found in similar locations on coastal areas along both Irish and UK coasts. The co-occurrence with sole, a more valuable target species, might predominantly affect UK beam trawl fleets in the sense that spatial avoidance strategies are unlikely to be effective in avoiding catches of plaice and maintaining catches of sole. 
This work is complementary to studies that have assessed the fishing suitability of an area based on discard per unit effort or discards to retained catch ratio (Viana et al. 2013; Grazia Pennino et al. 2014; Paradinas et al. 2016). We provide an overview of discard locations at multi species levels for both below and above MCRS discards in the central region of the Celtic Sea. It also sought to identify the spatial correspondence, or lack of, for discards above and below MCRS between countries and all countries combined. Previous analysis focused on discard to landings ratio, in this analysis we put the emphasis on discards only and distinguished $<$ and $>$ MCRS components because they have different implications in terms of management (Catchpole et al. 2014, 2017). It would then be interesting to investigate whether there is a link between > MCRS discards and landings quantities to better understand the link between the different components of the catches.

Scientific observer data represent the only detailed source of information on discarding practices at sea. However, they represent a very small proportion of fishing trips, between 1 and $3 \%$ at the national level. Putting together Irish, French and UK data has increased the number of observations, albeit without increasing the proportion of the fishing activities sampled. The robustness of our conclusions will still depend on how representative the national sampling actually is, and will only ever provide a partial view of discarding behaviour. The influence of variables that may significantly affect discarding risk - such as the seasonal and annual effects but also the use of different fishing gears, gear designs (e.g., mesh size), methods (e.g., time of day of fishing) or skipper effects have been investigated in the literature using modeling. However, considering the amount of data available through observer at sea programmes it is difficult to additionally account for spatial pattern at finer scales. It often requires interpolation methods to extend prediction to unobserved area. Multivariate analyses such as those used in this study are powerful to summarize big data sets and did find similarities between entities, nonetheless they have no predictive capabilities. Even with three national databases pooled together, it was difficult to disaggregate the data set into quarter or year without decreasing drastically the number of cells observed (reducing the overall picture of the entire area) and the number of FOs in each cells. Increasing the size of the cells can help overpassing these issues, but tradeoffs should be made to avoid having too large cells leading to spatial avoidance strategies that result in limited fishing activity over large areas. One way to improve the accuracy and precision of the maps and maybe look at shorter time periods (such as quarter for example), to account for seasonal migration of fish and spawning aggregations, could be to use similar data that could be collected by fishermen themselves. This could be through science-industry partnerships or use of finer logbook 
information, e.g. by haul rather than day or trip. The design and implementation of such partnerships is never straightforward (Kraan et al. 2013); but stakeholders are becoming more engaged in providing industry data in parallel to data collection programs to fill the gaps (Mangi et al. 2018).

The use of the type of spatial information at multispecies levels we have generated here by the fishing industry might appeal for more interactions between science and industry. Spatial management strategies may require additional (e.g finer spatial and temporal resolution and maybe real time) information (Little et al. 2015; Woods et al. 2018). The cluster analysis, the maps, and their subsequent analyses can help as a first approach to indicate the discarding risks of any particular area, but we should not be making decisions for the fishers. A further step would then be a more advanced modelling approach that would incorporate spatiotemporal effects and uncertainties and provides predictions on unobserved area. The main benefits of this work, and other similar work with observer data, will come from sharing the information in a format that fishermen can use to make decisions about their fishing operations. This could be as a risk map by species of what the likely issues with fishing in any given area might be. Other approaches can be real-time incentives using catch information. In that context, we could also envisage the use of web-based apps that can be interrogated by fishers before they sail and when at sea for single species and sizes or for different target and unwanted species. Similar approaches have been developed in the English Channel, $\mathrm{x}$ the Irish sea and the Celtic Sea (Reid and Fauconnet 2018).

\section{Acknowledgment}

This work has been funded by the European Union's Horizon 2020 research and innovation programme under Grant Agreement DiscardLess No 633680. 
Batsleer J, Hamon KG, van Overzee HMJ, et al (2015) High-grading and over-quota discarding in mixed fisheries. Rev Fish Biol Fish 25:715-736. doi: 10.1007/s11160-015-9403-0

Borges L, Rogan E, Officer R (2005) Discarding by the demersal fishery in the waters around Ireland. Fish Res 76:1-13. doi: 10.1016/j.fishres.2005.05.011

Calderwood J, Robert M, Pawlowski L, et al (In press) Hotspot mapping in the Celtic Sea: An interactive tool using multinational data to optimise fishing practices. Marine Policy

Catchpole TL, Feekings JP, Madsen N, et al (2014) Using inferred drivers of discarding behaviour to evaluate discard mitigation measures. ICES J Mar Sci 71:1277-1285. doi: 10.1093/icesjms/fst170

Catchpole TL, Frid CLJ, Gray TS (2005) Discards in North Sea fisheries: causes, consequences and solutions. Mar Pol 29:421-430. doi: 10.1016/j.marpol.2004.07.001

Catchpole TL, Ribeiro-Santos A, Mangi SC, et al (2017) The challenges of the landing obligation in EU fisheries. Mar Pol 82:76-86. doi: 10.1016/j.marpol.2017.05.001

Deporte N, Ulrich C, Mahévas S, et al (2012) Regional métier definition: a comparative investigation of statistical methods using a workflow applied to international otter trawl fisheries in the North Sea. ICES J Mar Sci 69:331-342. doi: 10.1093/icesjms/fsr197

Dolder PJ, Thorson JT, Minto C (2018) Spatial separation of catches in highly mixed fisheries. Sci Rep 8:13886. doi: 10.1038/s41598-018-31881-w

Eayrs S, Pol M (2018) The myth of voluntary uptake of proven fishing gear: investigations into the challenges inspiring change in fisheries. ICES J Mar Sci. doi: 10.1093/icesjms/fsy178

Eliasen SQ, Papadopoulou K-N, Vassilopoulou V, Catchpole TL (2014) Socio-economic and institutional incentives influencing fishers' behaviour in relation to fishing practices and discard. ICES J Mar Sci 71:1298-1307. doi: 10.1093/icesjms/fst120

Enever R, Revill A, Grant A (2007) Discarding in the English Channel, Western approaches, Celtic and Irish seas (ICES subarea VII). Fish Res 86:143-152. doi: 10.1016/j.fishres.2007.05.013

Erzini K, Costa ME, Bentes L, Borges TC (2002) A comparative study of the species composition of discards from five fisheries from the Algarve (southern Portugal). Fisheries Manag Ecol 9:31-40. doi: 10.1046/j.1365-2400.2002.00284.x

EU (2013) Regulation (EU) No 1380/2013 of the European Parliament and of the Council of 11 December 2013 on the Common Fisheries Policy, amending Council Regulations (EC) No 1954/2003 and (EC) No 1224/2009 and repealing Council Regulations (EC) No 2371/2002 and (EC) No 639/2004 and Council Decision 2004/585/EC

Evans K, Weninger Q (2014) Information Sharing and Cooperative Search in Fisheries. Environmental \& Resource Economics 58:353-372

Fauconnet L, Rochet M-J (2016) Fishing selectivity as an instrument to reach management objectives in an ecosystem approach to fisheries. Mar Pol 64:46-54. doi: 10.1016/j.marpol.2015.11.004

Feekings J, Bartolino V, Madsen N, Catchpole T (2012) Fishery Discards: Factors Affecting Their Variability within a Demersal Trawl Fishery. PLoS One 7:e36409. doi: 10.1371/journal.pone.0036409

Fraser HM, Greenstreet SPR, Fryer RJ, Piet GJ (2008) Mapping spatial variation in demersal fish species diversity and composition in the North Sea: accounting for species and size-related catchability in survey trawls. ICES J Mar Sci 65:531-538. doi: 10.1093/icesjms/fsn 036 
Fryer RJ, O’Neill FG, Edridge A (2016) A meta-analysis of haddock size-selection data. Fish Fish 17:358-374. doi: $10.1111 /$ faf.12107

Fryer RJ, Summerbell K, O’Neill FG (2017) A meta-analysis of vertical stratification in demersal trawl gears. Can J Fish Aquat Sci 74:1243-1250. doi: 10.1139/cjfas-2016-0391

GearingUp (2017) https://tool.gearingup.eu/. https://tool.gearingup.eu/

Gerritsen H, Lordan C (2011) Integrating vessel monitoring systems (VMS) data with daily catch data from logbooks to explore the spatial distribution of catch and effort at high resolution. ICES J Mar Sci 68:245-252. doi: 10.1093/icesjms/fsq137

Gerritsen HD, Lordan C, Minto C, Kraak SBM (2012) Spatial patterns in the retained catch composition of Irish demersal otter trawlers: High-resolution fisheries data as a management tool. Fish Res 129:127-136. doi: 10.1016/j.fishres.2012.06.019

Grazia Pennino M, Munoz F, Conesa D, et al (2014) Bayesian spatio-temporal discard model in a demersal trawl fishery. J Sea Res 90:44-53. doi: 10.1016/j.seares.2014.03.001

ICES (2018) Celtic Seas ecoregion? Fisheries overview, including mixed-fisheries considerations. ICES. doi: 10.17895/ices.pub.4640

Kacher M, Amara R (2005) Distribution and growth of 0-group European hake in the Bay of Biscay and Celtic Sea: a spatial and inter-annual analyses. Fish Res 71:373-378. doi: 10.1016/j.fisheries.2004.08.034

Kelleher K (2005) Discards in the World's Marine Fisheries - An Update. 131

Kraan M, Uhlmann S, Steenbergen J, et al (2013) The optimal process of self-sampling in fisheries: lessons learned in the Netherlands. J Fish Biol 83:963-973. doi: 10.1111/jfb.12192

Legendre P, Legendre L (2012) Numerical Ecology, Volume 24 - 3rd Edition

Little AS, Needle CL, Hilborn R, et al (2015) Real-time spatial management approaches to reduce bycatch and discards: experiences from Europe and the United States. Fish Fish 16:576-602. doi: $10.1111 /$ faf. 12080

Macdonald P, Cleasby IR, Angus CH, Marshall CT (2014) The contribution of quota to the discards problem: a case study on the complexity of common megrim Lepidorhombus whiffiagonis discarding in the northern North Sea. ICES J Mar Sci 71:1256-1265. doi: 10.1093/icesjms/fsu009

Maina I, Kavadas S, Machias A, et al (2018) Modelling the spatiotemporal distribution of fisheries discards: A case study on eastern Ionian Sea trawl fishery. J Sea Res 139:10-23. doi: 10.1016/j.seares.2018.06.001

Mangi SC, Kupschus S, Mackinson S, et al (2018) Progress in designing and delivering effective fishing industry-science data collection in the UK. Fish Fish 19:622-642. doi: 10.1111/faf.12279

Martinez I, Ellis JR, Scott B, Tidd A (2013) The fish and fisheries of Jones Bank and the wider Celtic Sea. Prog Oceanogr 117:89-105. doi: 10.1016/j.pocean.2013.03.004

Mateo M, Pawlowski L, Robert M (2017) Highly mixed fisheries: fine-scale spatial patterns in retained catches of French fisheries in the Celtic Sea. ICES J Mar Sci 74:91-101. doi: 10.1093/icesjms/fsw129

Maxwell DL, Stelzenmueller V, Eastwood PD, Rogers SI (2009) Modelling the spatial distribution of plaice (Pleuronectes platessa), sole (Solea solea) and thornback ray (Raja clavata) in UK waters for marine management and planning. J Sea Res 61:258-267. doi: 10.1016/j.seares.2008.11.008 
Moore C, Davie S, Robert M, et al (2019) Defining métier for the Celtic Sea mixed fisheries: A multiannual international study of typology. Fisheries Research 219:105310. doi: 10.1016/j.fishres.2019.105310

Morandeau G, Macher C, Sanchez F, et al (2014) Why do fishermen discard? Distribution and quantification of the causes of discards in the Southern Bay of Biscay passive gear fisheries. Marine Policy 48:3038. doi: 10.1016/j.marpol.2014.02.022

O’Neill FG, Mutch K (2017) Selectivity in Trawl Fishing Gears. Scottish Marine and Freshwater Science Vol 8 No 01

Paradinas I, Marin M, Grazia Pennino M, et al (2016) Identifying the best fishing-suitable areas under the new European discard ban. ICES J Mar Sci 73:2479-2487. doi: 10.1093/icesjms/fsw114

Pennino MG, Vilela R, Valeiras J, Bellido JM (2017) Discard management: A spatial multi-criteria approach. Mar Pol 77:144-151. doi: 10.1016/j.marpol.2016.12.022

Pérez R, Gilman E, Huntington T, et al (2019) A third assessment of global marine fisheries discards. FAO Fisheries and Aquaculture Technical Paper No. 633. Rome, FAO. 78 pp

Persohn C, Lorance P, Trenkel VM (2009) Habitat preferences of selected demersal fish species in the Bay of Biscay and Celtic Sea, North-East Atlantic. Fish Oceanogr 18:268-285. doi: 10.1111/j.13652419.2009.00515.x

Pointin F, Cornou A-S, Prod'homme R, et al (2018) A method to address the non-random spatial distribution of on-board observer data to map landings and discards. Fish Res 199:242-251. doi: 10.1016/j.fishres.2017.10.023

Reid D, Fauconnet L (2018) Decision support tool for fishers incorporating information from tasks 4.1, 4.2 and information on unwanted catches derived from scientific data. DiscardLess deliverable D4.3.

Rochet MJ, Peronnet I, Trenkel VM (2002) An analysis of discards from the French trawler fleet in the Celtic Sea. ICES J Mar Sci 59:538-552. doi: 10.1006/jmsc.2002.1182

Schrope M (2010) Fisheries: What's the catch? Nature 465:540-542. doi: 10.1038/465540a

SeaFish (2018) https://www.seafish.org/geardb/

Sharples J, Ellis JR, Nolan G, Scott BE (2013) Fishing and the oceanography of a stratified shelf sea. Prog Oceanogr 117:130-139. doi: 10.1016/j.pocean.2013.06.014

Sigurdardottir S, Stefansdottir EK, Condie H, et al (2015) How can discards in European fisheries be mitigated? Strengths, weaknesses, opportunities and threats of potential mitigation methods. Mar Pol 51:366-374. doi: 10.1016/j.marpol.2014.09.018

Sims M, Cox T, Lewison R (2008) Modeling spatial patterns in fisheries bycatch: Improving bycatch maps to aid fisheries management. Ecol Appl 18:649-661. doi: 10.1890/07-0685.1

Verdoit M (2003) Are commercial logbook and scientific CPUE data useful for characterizing the spatial and seasonal distribution of exploited populations? The case of the Celtic Sea whiting. Aquatic Living Resources 16:467-485. doi: 10.1016/j.aquliv.2003.07.002

Viana M, Jackson AL, Graham N, Parnell AC (2013) Disentangling spatio-temporal processes in a hierarchical system: a case study in fisheries discards. Ecography 36:569-578. doi: 10.1111/j.16000587.2012.07853.x

Vilela R, Maria Bellido J (2015) Fishing suitability maps: helping fishermen reduce discards. Can J Fish Aquat Sci 72:1191-1201. doi: 10.1139/cjfas-2013-0522 
691

692

693

694

695

696

697

698

699

700

701

702

703

704

705

706

707

708

709

710

711

712

713

714

715

716

717

718

719

720

721
Woods PJ, Elvarsson BT, Sigurdsson T, Stefansson G (2018) Evaluating the effectiveness of real-time closures for reducing susceptibility of small fish to capture. ICES J Mar Sci 75:298-308. doi: 10.1093/icesjms/fsx152

Zeller D, Cashion T, Palomares M, Pauly D (2018) Global marine fisheries discards: A synthesis of reconstructed data. Fish Fish 19:30-39. doi: 10.1111/faf.12233 
Figure 1. Discard maps of $<M C R S$ (a) and $>$ MCRS (b) fish for Ireland. Discard maps of $<M C R S$ (c) and $>M C R S$ (d) fish for France, Discard maps of $<M C R S(e)$ and $>M C R S$ (f) fish for UK.

(a) IR $<$ MCRS

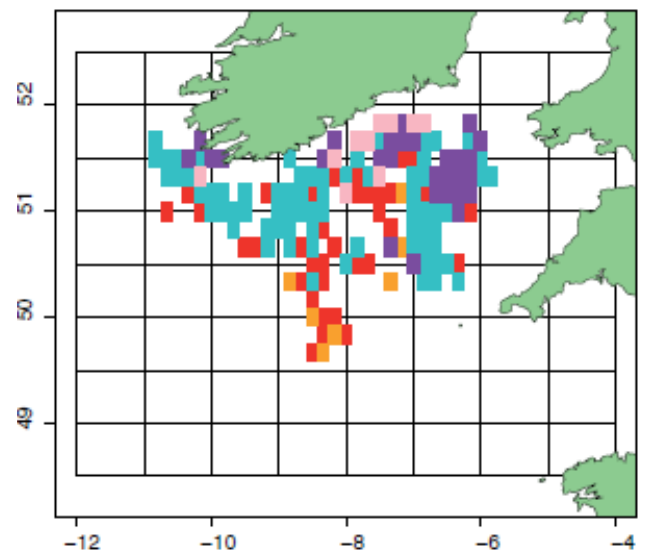

(c) FR < MCRS

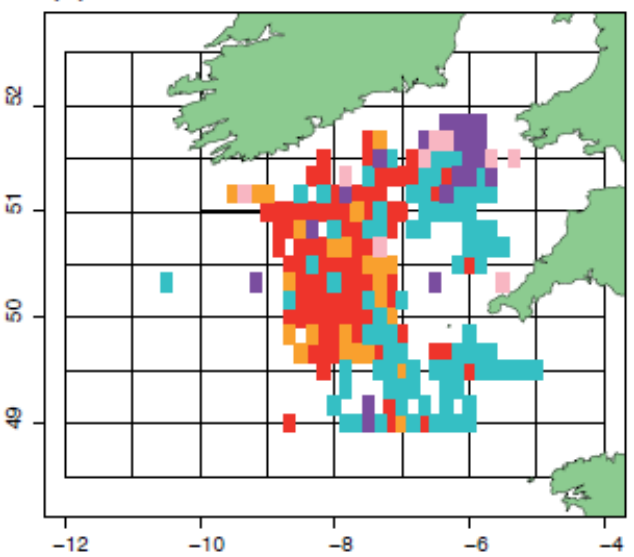

(e) UK $<$ MCRS

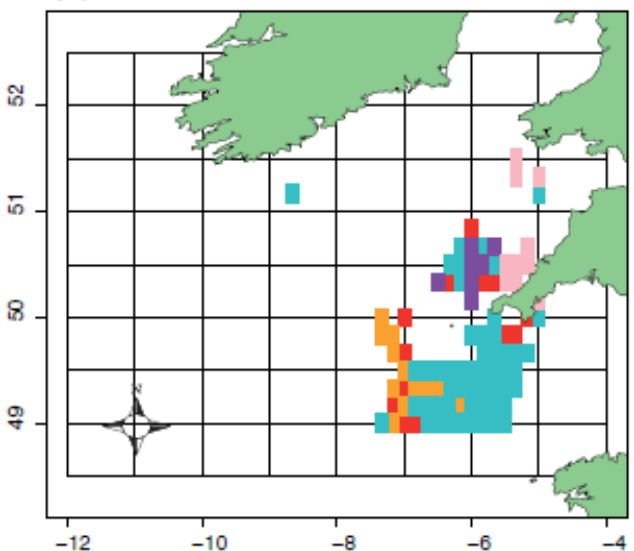

(b) IR > MCRS

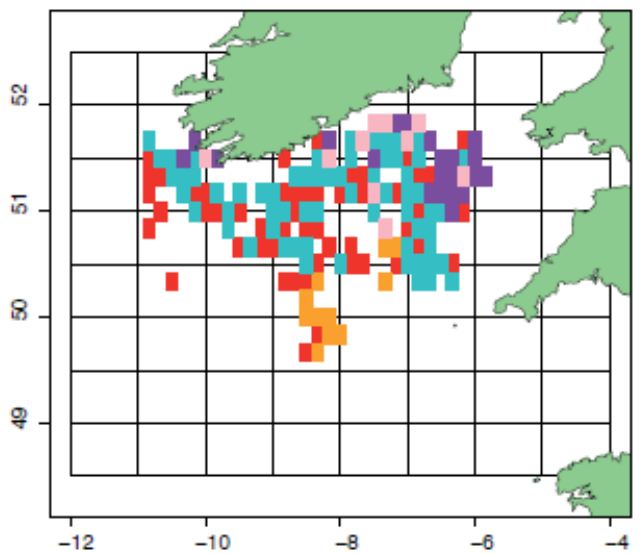

(d) FR > MCRS

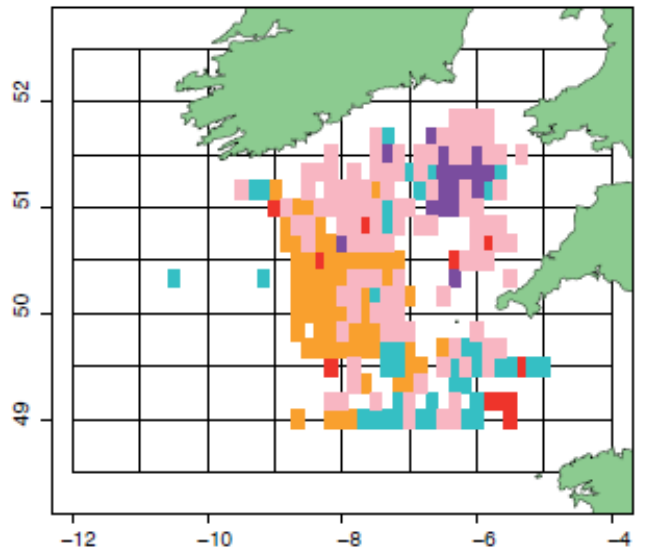

(f) UK > MCRS

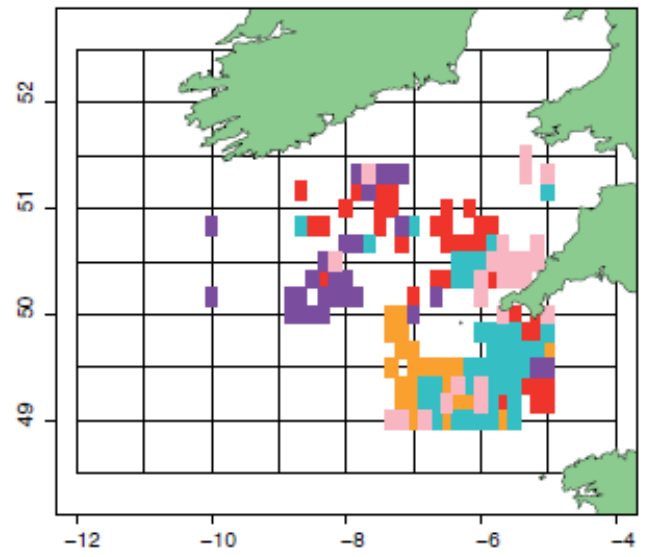


Figure 2. Bar plots illustrating in which proportion the cells of each cluster of undersized discards are classified in oversized discards clusters. If all cells classified as cluster 1 for undersized discards were also classified in cluster 1 for oversized discards, the first bar would be entirely red.
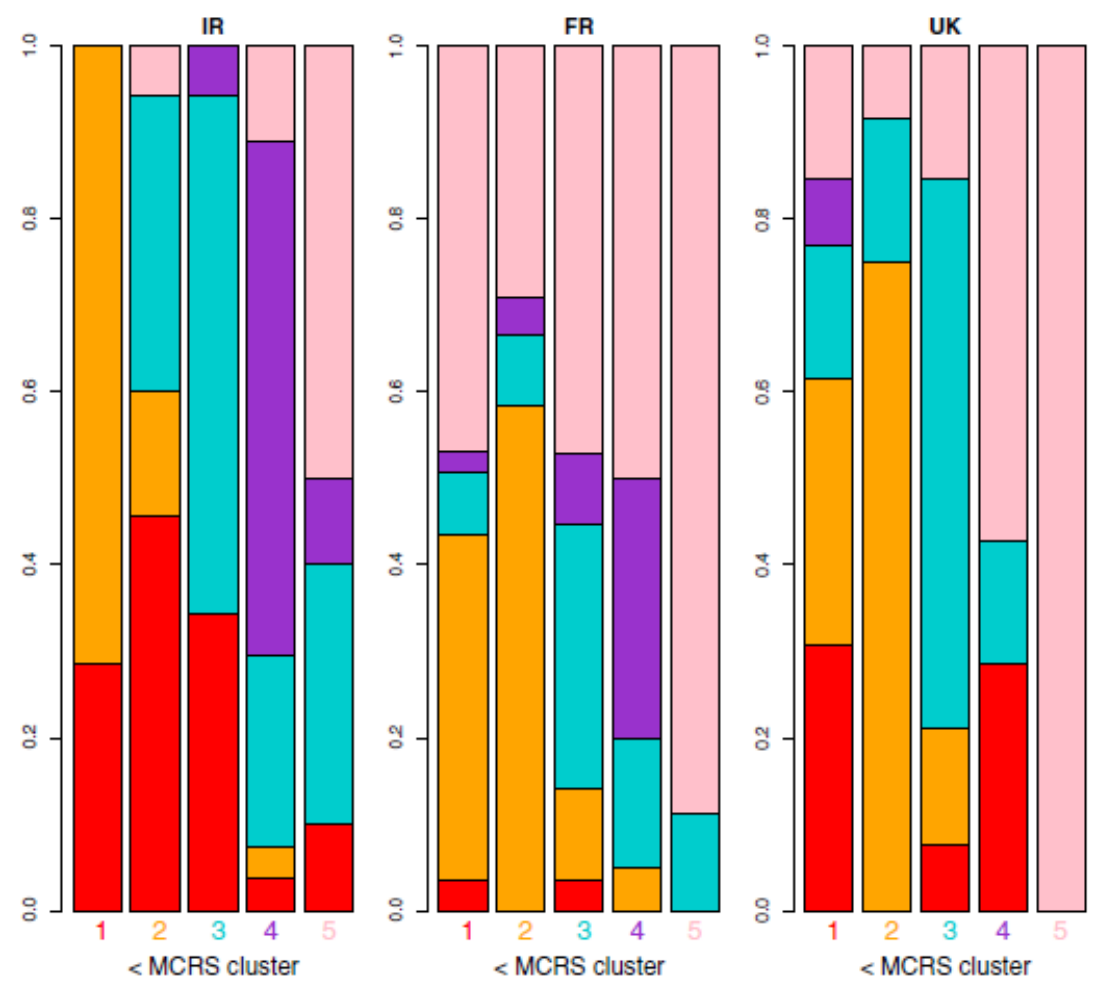

733

Figure 3. Discard maps of <MCRS (a) and $>$ MCRS (b) fish for Ireland, France and UK data analyzed together.

(a) ALL $<$ MCRS

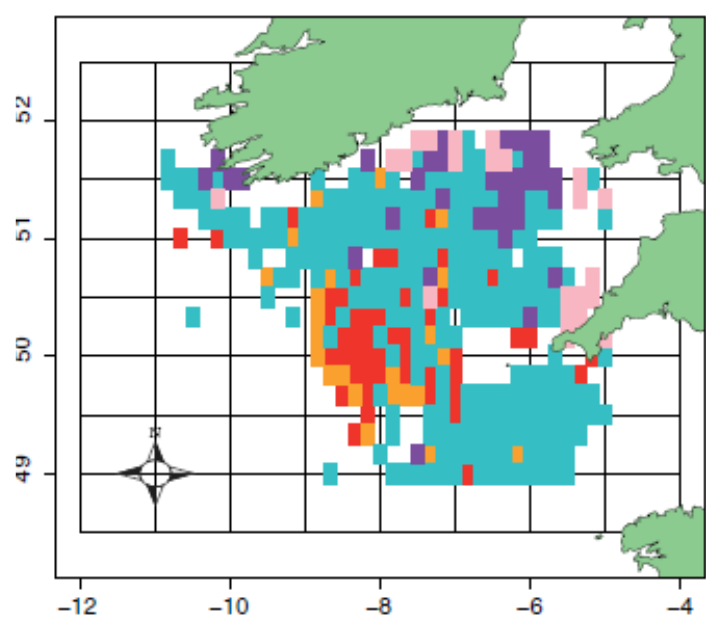

(b) ALL > MCRS

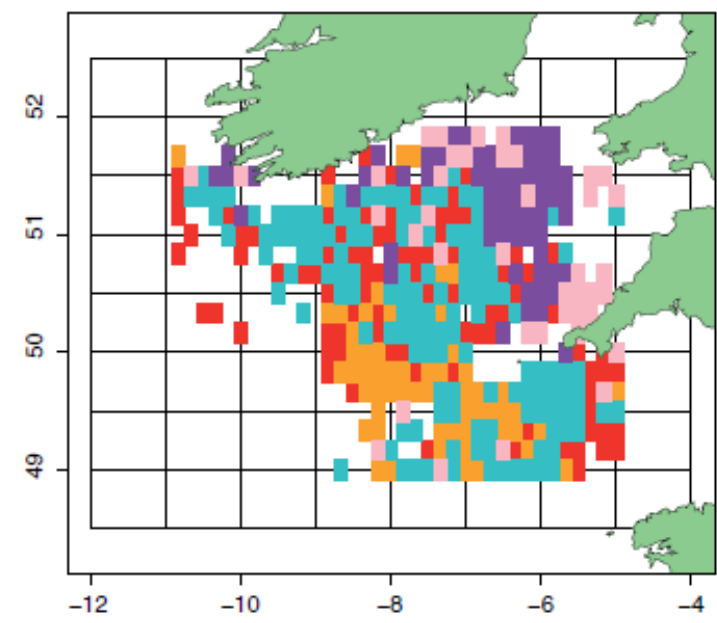

LONGITUDE

$\square$ Cluster 1 व Cluster $2 \square$ Cluster 3 व Cluster $4 \square$ Cluster 5

Figure 4. Overlapping maps of cluster for international and national data for cluster 8(a-b) and cluster 1 (c-d) and for $<$ MCRS discards $(a, c)$ and $>$ MCRS discards $(b, d)$. 
(a) C8 $<$ MCRS

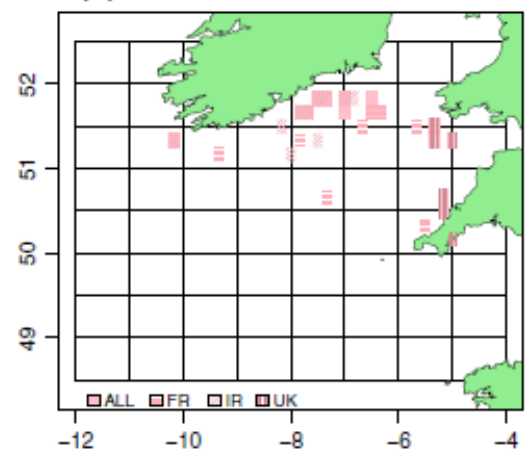

(c) C1 < MCRS

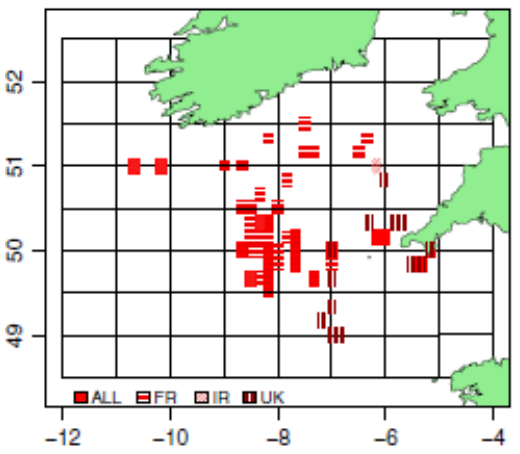

(b) $\mathrm{C} 8>$ MCRS

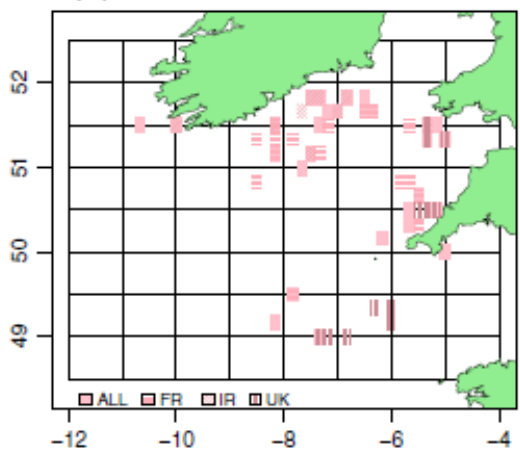

(d) $\mathrm{C} 1>\mathrm{MCRS}$

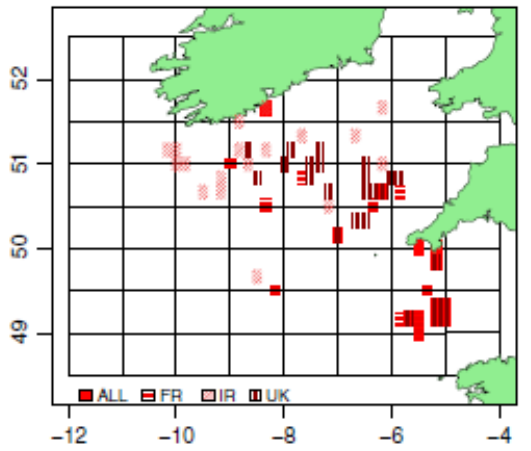

Figure 5. Overlapping maps of < and $>$ MCRS discards for cluster 9 based on a) all data combined, b) Irish data, 741 c) French data and d) UK data.

(a) ALL

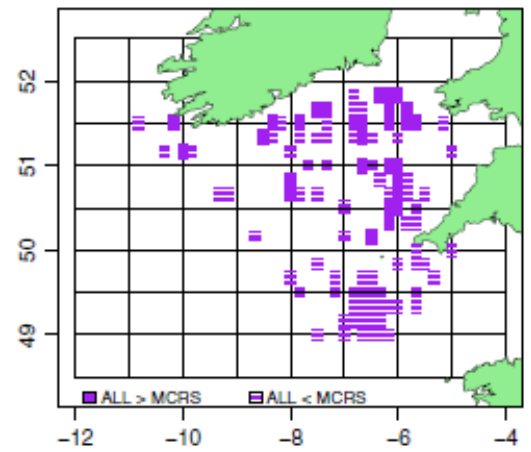

(c) FR

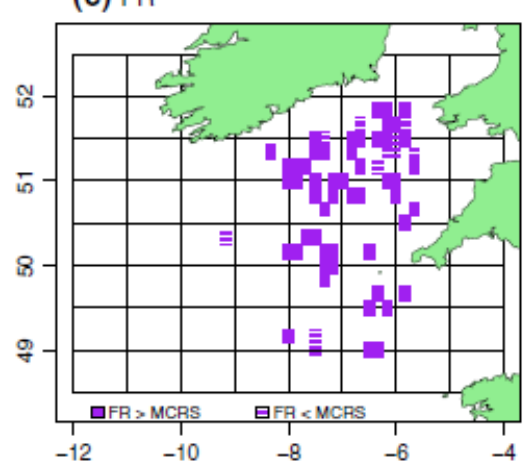

(b) IR

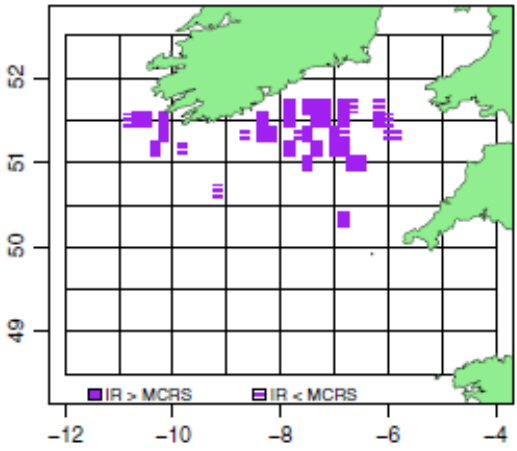

(d) UK

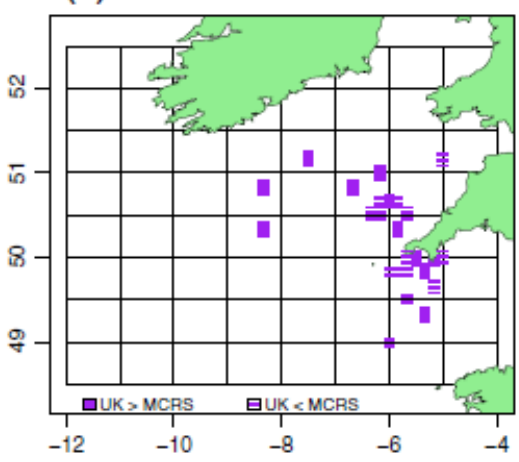


Table 1. Relative abundance for each species in clusters of < and $>$ MCRS discards for Ireland (a), France (b),

\begin{tabular}{|c|c|c|c|c|c|c|c|c|c|c|}
\hline \multirow{2}{*}{ a) IR } & \multicolumn{5}{|c|}{$<$ MCRS Cluster } & \multicolumn{5}{|c|}{$>$ MCRS Cluster } \\
\hline & & 2 & 3 & & 5 & & 2 & 3 & & \\
\hline & .62 & 0.09 & 0.12 & 0.14 & 0.03 & 0.58 & 0.07 & 0.12 & 0.14 & 0.09 \\
\hline Megrim & 16 & 0.81 & 0.01 & 0.00 & 0.03 & 0.09 & 0.64 & 0.12 & 0.02 & 0.13 \\
\hline Haddock & 0.24 & 0.02 & 0.44 & 0.22 & 0.09 & 0.22 & 0.02 & 0.48 & 0.17 & 0.12 \\
\hline whiting & 0.04 & 0.00 & 0.08 & 0.75 & 0.13 & 0.07 & 0.01 & 0.12 & 0.64 & 0.15 \\
\hline Hake & 15 & 0.69 & 0.02 & 0.06 & 0.09 & 0.47 & 0.15 & 0.14 & 0.04 & 0.20 \\
\hline Plaice & 0.08 & 0.00 & 0.04 & 0.10 & 0.78 & 0.05 & 0.01 & 0.13 & 0.07 & 0.75 \\
\hline Sole & 0.00 & 0.00 & 0.00 & 0.81 & 0.19 & 0.01 & 0.00 & 0.07 & 0.10 & 0.82 \\
\hline \multicolumn{11}{|l|}{ b) $F R$} \\
\hline & & 2 & 3 & & 5 & & 2 & 3 & & 5 \\
\hline cod & 0.73 & 0.10 & 0.05 & 0.10 & 0.03 & 0.79 & 0.07 & 0.01 & 0.01 & 0.11 \\
\hline Megrim & 0.12 & 0.87 & 0.00 & 0.01 & 0.00 & 0.12 & 0.66 & 0.06 & 0.06 & 0.10 \\
\hline Haddock & 0.23 & 0.15 & 0.41 & 0.19 & 0.02 & 0.04 & 0.07 & 0.53 & 0.09 & 0.27 \\
\hline whitin & 0.04 & 0.05 & 0.03 & 0.88 & 0.01 & 0.04 & 0.05 & 0.04 & 0.72 & 0.15 \\
\hline Hake & 0.10 & 0.84 & 0.03 & 0.03 & 0.00 & 0.16 & 0.64 & 0.01 & 0.03 & 0.16 \\
\hline Plaice & 04 & 0.01 & 0.01 & 0.05 & 0.89 & 0.08 & 0.09 & 0.03 & 0.14 & 0.66 \\
\hline Sole & 00 & 1.00 & 0.00 & 0.00 & 0.00 & 0.00 & 0.00 & 0.00 & 0.05 & 0.95 \\
\hline \multicolumn{11}{|l|}{ c) UK } \\
\hline & & 2 & 3 & & & & & 3 & & 5 \\
\hline cod & 0.58 & 0.15 & 0.06 & 0.16 & 0.06 & 0.54 & 0.03 & 0.09 & 0.24 & 0.10 \\
\hline Megrim & 0.15 & 0.72 & 0.13 & 0.00 & 0.00 & 0.01 & 0.64 & 0.21 & 0.02 & 0.12 \\
\hline Haddock & 0.13 & 0.19 & 0.47 & 0.19 & 0.03 & 0.07 & 0.11 & 0.64 & 0.03 & 0.15 \\
\hline whiti & 0.02 & 0.01 & 0.06 & 0.85 & 0.07 & 0.10 & 0.04 & 0.15 & 0.17 & 0.55 \\
\hline Hake & 0.05 & 0.65 & 0.05 & 0.25 & 0.00 & 0.05 & 0.08 & 0.06 & 0.75 & 0.06 \\
\hline Plaice & 0.11 & 0.03 & 0.04 & 0.12 & 0.70 & 0.01 & 0.06 & 0.11 & 0.00 & 0.81 \\
\hline Sole & 0.03 & 0.00 & 0.07 & 0.00 & 0.90 & 0.00 & 0.06 & 0.13 & 0.00 & 0.81 \\
\hline \multicolumn{11}{|l|}{ d) ALL } \\
\hline cod & & 2 & 3 & & 5 & & 2 & 3 & & 5 \\
\hline Megrim & 0.67 & 0.01 & 0.13 & 0.12 & 0.06 & 0.56 & 0.08 & 0.09 & 0.10 & 0.16 \\
\hline Haddock & 0.21 & 0.73 & 0.05 & 0.00 & 0.01 & 0.08 & 0.64 & 0.17 & 0.03 & 0.08 \\
\hline whiting & 0.19 & 0.06 & 0.46 & 0.25 & 0.05 & 0.12 & 0.07 & 0.43 & 0.27 & 0.11 \\
\hline Hake & 0.03 & 0.02 & 0.06 & 0.78 & 0.11 & 0.06 & 0.04 & 0.09 & 0.58 & 0.23 \\
\hline Plaic & 0.17 & 0.71 & 0.03 & 0.05 & 0.04 & 0.43 & 0.21 & 0.18 & 0.06 & 0.12 \\
\hline \multirow[t]{2}{*}{ Sole } & 0.0 & 0.01 & 0.05 & 0.06 & 0.85 & 0.04 & 0.08 & 0.07 & 0.08 & 0.73 \\
\hline & 0.00 & 0.00 & 0.04 & 0.03 & 0.93 & 0.00 & 0.04 & 0.05 & 0.03 & 0.87 \\
\hline
\end{tabular}


761 Table 2. Mean percentage of TAC uptake by stock and countries between 2010 and 2014. Data comes from both ICES advice sheets for each stocks (http://www.ices.dk/community/advisory-process/Pages/Latest(https://ec.europa.eu/fisheries/cfp/fishing_rules/tacs).

\section{5}

\begin{tabular}{|c|c|c|c|c|c|c|c|c|c|c|}
\hline \multirow[t]{2}{*}{ Stock (ICES area) } & \multicolumn{2}{|c|}{ Cod (7ek) } & \multicolumn{2}{|c|}{ Haddock (7bk) } & \multicolumn{2}{|c|}{ Whiting (7bk) } & \multicolumn{2}{|c|}{ Plaice (7fg) } & \multicolumn{2}{|c|}{ Plaice (7hjk) } \\
\hline & Mean & $\mathrm{SD}$ & Mean & SD & Mean & SD & Mean & SD & Mean & SD \\
\hline Belgium & 47.5 & 12.3 & 120.7 & 18.9 & 88.8 & 20.9 & 352.7 & 78.1 & 57.3 & 34.7 \\
\hline \multicolumn{11}{|l|}{ Spain } \\
\hline France & 63.0 & 15.1 & 94.3 & 9.8 & 38.0 & 7.5 & 122.8 & 20.1 & 301.0 & 54.9 \\
\hline Ireland & 114.5 & 12.7 & 102.1 & 10.8 & 106.6 & 13.9 & 33.8 & 6.3 & 97.0 & 38.5 \\
\hline Netherlands & 0.0 & 0.0 & & & & & & & 0.0 & 0.0 \\
\hline UK & 87.7 & 12.2 & 99.6 & 21.2 & 43.9 & 8.8 & 80.6 & 25.4 & 183.1 & 62.2 \\
\hline Average discard rate & 14.0 & 13.0 & 37.8 & 19.6 & 20.3 & 4.0 & 70.7 & 6.0 & & \\
\hline Total uptake based on landings only & 72.5 & 13.3 & 97.6 & 8.7 & 58.6 & 7.1 & 104.5 & 12.6 & 100.8 & 16.9 \\
\hline Total uptake based on catches & 87.0 & 28.1 & 169.6 & 50.9 & 73.9 & 11.6 & 368.4 & 82.0 & 100.8 & 16.9 \\
\hline \multirow[t]{2}{*}{ Stock (ICES area) } & \multicolumn{3}{|c|}{ Sole (7fg) } & \multicolumn{2}{|c|}{ Sole (7hjk) } & \multicolumn{2}{|c|}{ Hake (6-7) } & & \multicolumn{2}{|c|}{ Megrim (7) } \\
\hline & Me: & & SD & Mean & SD & Mean & SD & & Mean & SD \\
\hline Belgium & 110 & & 11.7 & 54.4 & 45.8 & 7.6 & 1.1 & & 79.1 & 39.2 \\
\hline Spain & & & & & & 141.5 & 15.3 & & 68.5 & 10.9 \\
\hline France & 74 & & 11.1 & 113.1 & 14.2 & 93.2 & 22.9 & & 45.3 & 10.1 \\
\hline Ireland & 95 . & & 17.7 & 40.9 & 7.6 & 109.4 & 7.0 & & 90.0 & 16.1 \\
\hline Netherlands & & & & 0.0 & 0.0 & 94.6 & 65.1 & & & \\
\hline UK & 65 & & 15.2 & 71.1 & 8.6 & 83.5 & 11.1 & & 104.9 & 14.6 \\
\hline Average discard rate & 2. & & 0.6 & & & 13.5 & 6.1 & & 19.6 & 5.7 \\
\hline Total uptake based on landings only & 95. & & 9.7 & 53.7 & 5.8 & 105.9 & 13.7 & & 69.1 & 10.8 \\
\hline Total uptake based on catches & 97. & & 11.0 & 53.7 & 5.8 & 113.3 & 23.1 & & 85.8 & 10.0 \\
\hline
\end{tabular}

766

767

768

769 